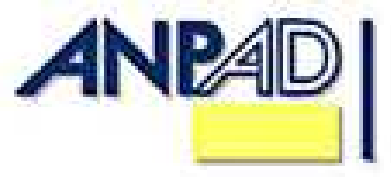

Available online at http://www.anpad.org.br/bar

\title{
Intellectual Capital and Organizational Renewal: Building Dynamic Capabilities through People
}

Fabio de Biazzi * E-mail address: fabiodebiazzi@yahoo.com.br Insper Instituto de Ensino e Pesquisa São Paulo, SP, Brazil.

* Corresponding author: Fabio de Biazzi

Insper Executive MBA Program, Rua Quata, 300, Vila Olímpia, São Paulo, SP, 04546-042, Brazil.

Copyright (C) 2012 Brazilian Administration Review. All rights reserved, including rights for translation. Parts of this work may be quoted without prior knowledge on the condition that the source is identified. 


\begin{abstract}
This paper seeks to deepen the understanding of management practices adopted by organizations characterized by significant levels of participation and influence from their employees. Based on the assumption that the successful utilization of such practices is circumstantial, a conceptual framework is proposed identifying the essential elements that should be dynamically aligned to allow organizational success in the long term. Different types of work \& participation practices - that arise from the adoption of the dimensions locus of knowledge and locus of power - support the reasoning on how to align these elements and, consequently, how to lead the organizational renewal and survival in the long run.
\end{abstract}

Key words: work and participation practices; dynamic capabilities; human resource management; intellectual capital; organization ambidexterity. 


\section{Introduction}

The pursuit of dynamic capabilities (Harreld, O'Reilly, \& Tushman, 2007, p. 24) that lead to sustainable growth and long-term survival has been the focus of several recent studies, and reaching them is a dream - or a nightmare - for those in top management positions. Individuals and teams - and their different kinds of arrangements - can be seen as an important part of the equation: high performance working teams, collaboration, decentralization, autonomy, and empowerment are frequently presented as paths to reach such capabilities. These paths do not develop at random, but are due mainly to two trends that have been transforming work throughout decades: (a) an increasingly educated workforce, capable and eager to learn and continuously develop; and (b) technological development that, after substantially diminishing manual work at companies and significantly increasing productivity, has drastically reduced the cost of processing information and communications. Today people can make specific contributions with high intellectual contents, and individuals and teams also emerge as essential assets for the creation of value and work more efficiently in more collaborative and informal organizational arrangements (Pfeffer, 1998). In the same direction, new information technologies make it more possible and desirable to attain more decentralized and empowered forms of work organization (Malone, 2004).

However, the reality of current management practices does not necessarily point toward this trend. Empirical evidence - as summarized by the Centre for Decision Making Studies of the Tavistock Institute - reveals a limitation to the levels of participation and influence non-managerial functions have in organizations (Heller, 1998a). Even earlier studies, such as those of Locke and Schweiger (1990), have already shown that the efficacy of participative solutions is strongly dependent on other contextual factors - not only technology - and that they do not necessarily lead to more efficiency.

These apparent contradictions indicate that higher levels of participation and engagement, although more desirable and possible than ever, are neither simple paths, nor immediately applicable to the various organizational situations. 50 years ago, Drucker (1999) introduced the concept of the knowledge worker in order to define well-prepared and sophistically educated individuals capable of making specific contributions with high intellectual content. Only 10 years ago, the same Drucker (1999) asserted that the main challenge to be faced by the managers of the 21 st century would be how to increase the productivity of these much better prepared workers, immerged in situations of higher technological content. Similarly, Welch $(2005$, p. 56) underscored the need to give "voice and dignity" to individuals and call on managers to bring "every brain into the game". Adler, Heckscher and Prusak (2011, p. 97) argued that long-term success depends on shared purpose, an ethic of contribution, processes that enable people to work in a flexible and disciplined way and culture and practices "in which collaboration is valued and rewarded".

And what should we do to engage, to focus people's energy on making significant contributions, to have them working collaboratively, and to take real advantage of participation in order to survive in the long run? Parker, Wall and Cordery (2001, p. 432) suggest that a conceptual framework should describe the relationships among work "characteristics, relevant factors, results, mechanisms, and contingences". This paper aims to identify and show the inter-relations among the key elements for the attainment of the appropriate equation for levels of autonomy and participation of individuals and teams in organizations. Following this perspective, the author proposes that competences, motivation, work \& participation practices, human resource policies, technology, and culture be seen in an integrated and systems-thinking perspective, a powerful dynamic way of comprehension still underutilized by organizations (Ackoff, 2006).

The main premise adopted here is that - if worked in a consistent and systemic mode - these elements are capable of leading organizations to higher levels of competitiveness and adaptation - or borrowing a remark from O'Reilly and Tushman (2011, p. 19), allowing organizations "to survive in the face of change". Thus, an organization's success depends on the dynamic adjustment among its 
work organization practices and people management policies, its technological choices and the predominant modes of behavior and relationship among its components and culture. These same organization and management tools need to be applied and consistent when we look at each individual, with their unique features in terms of skills and engagement, that is, competences and motivation.

\section{The Elements of the 'Triple Scull' Framework}

The engagement of and the opportunity for each individual to contribute to the organization occur, first of all, in the interaction with one's immediate superior, in responsibilities that are trusted to him/her, within the scope and autonomy given for him/her to perform these tasks, and in the subsequent possibility for learning and growing. Both the employee and superior are responsible for the dynamics to be established, but undoubtedly the role and capacity to control the situation are much more in the hands of those in a higher position in the hierarchy.

Individual performance and its management do not happen in an empty or inert environment. If the performance of tasks and functions depends directly on skills and motivations, the ways in which individuals interact with their colleagues and the intrinsic content of these same tasks also depend on two conditions given by the organization and over which individuals have little impact: technological bases and cultural bases. On one hand, the alternatives that will make sense in a certain situation will depend on the limitations or possibilities resulting from the technological choices made by the organization; for example, a given automatic call distribution software adopted in a call center. On the other hand, the relationships between individuals and their immediate superiors, peers and other colleagues will be guided by the values, objectives and beliefs shared by this group of people, and by the level of trust in the organization in general, particularly in the immediate manager and specifically among peers. Individual and group perform according to the very unique features of each organization, based on its technological choices and on the values shared by its members.

Last, an organization that wants to extract what is best from its employees will then need to not only build skills in its managers for them to balance abilities and motivations with individual tasks, but also to establish convenient Work \& Participation Practices and introduce the application of Human Resource Policies consistent with these same practices. Individuals need to be managed respecting their competences and motivations. In turn, teams and areas need to have their processes - and management policies - organized so as to enable the contributions and engagement of individuals and groups of individuals. Thus, the organization will also need to establish these practices and policies in a systematic and integrated fashion, which will bridge performance and management of individuals and the cultural and technological bases upon which the functioning of the organization lies.

Thus, building an organization in which individuals' and teams' work enable it to successfully exploit mature business and explore new ones requires: (a) the management of tasks, capacities and motivations at the individual level; (b) the design of Work \& Participation Practices and defining Human Resources Policies consistent among themselves; and (c) consistent with the technological choices and characteristics of the processes for the production of goods, services and/or information, and that are also aligned with the shared values, proposals, beliefs, and behaviors. By selecting and combining these elements, the author has developed the Triple Scull Framework (Figure 1). 


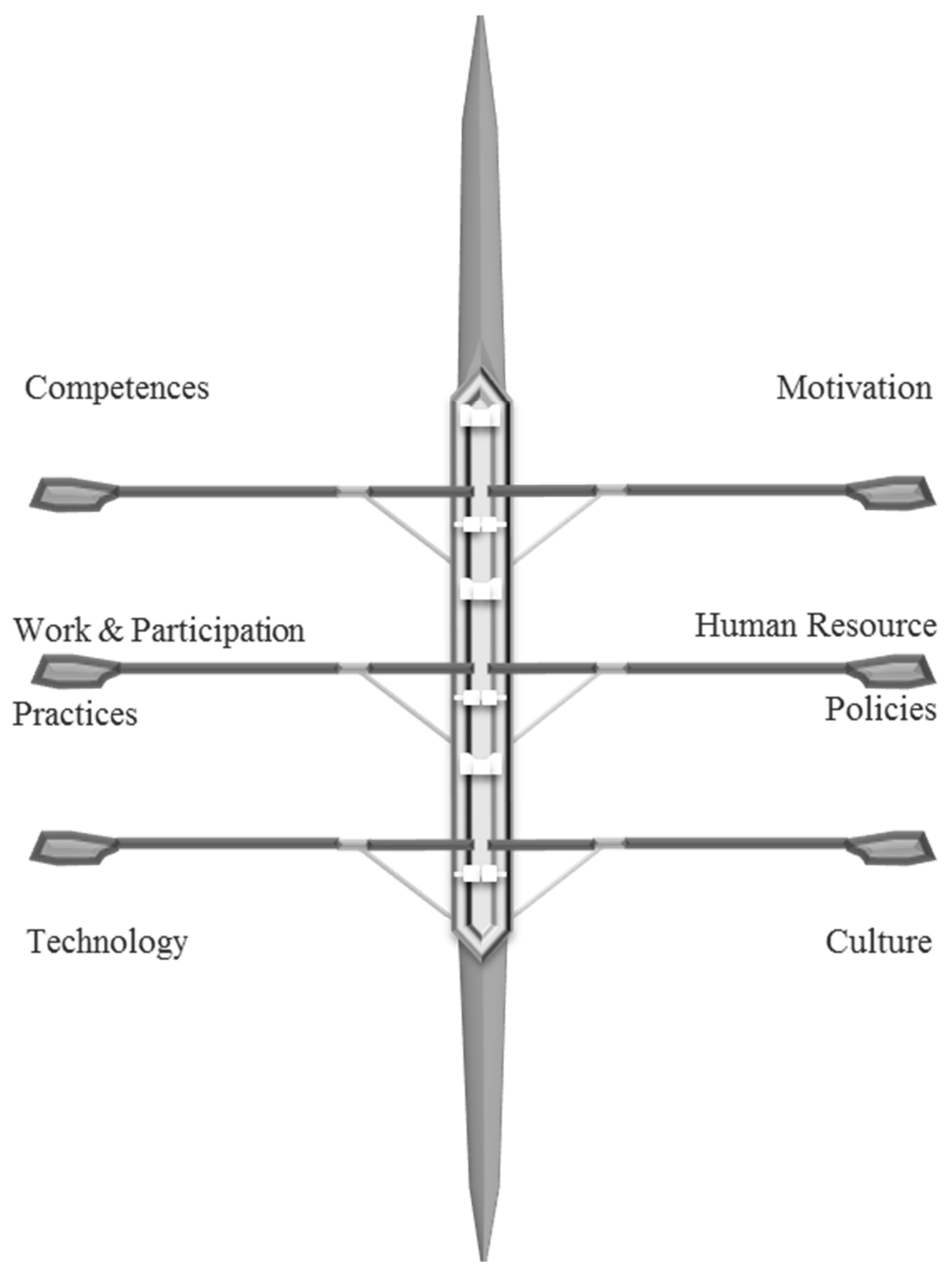

Figure 1. The Triple Scull Framework.

Source: Elaborated by the author.

Although a real triple scull boat does not exist, this representation can help us to understand the mechanics of creating sustainable competitive advantage/dynamic capabilities: (a) at individual level there is interaction between motivation and competences, forming the first line of oars; (b) at the organizational level there are the influences of culture and technology, the third line of oars; (c) in the middle, the second line of oars operates the articulation between the individual and the organizational levels, presenting the practices and policies. In order to succeed, however, the harmonization must involve all six oars, forming a consistent, coherent and dynamically adjusted set of elements. The six elements form the basis for the execution of a given strategy, and the "scull" points at the "strategic insight", as it is defined by Harreld, O'Reilly and Tushman (2007, p. 29), that sets an overall direction by considering goals, the understanding of customer needs, competitor moves and technological developments, innovation focus and business design (customer selection, value proposition, value capture and scope of activities).

\section{Competences}

The first element to be considered - when seeking to increase individual contribution and have individuals strongly dedicated not only to work, but to its improvement and to the solution of problems - is one's competence. Competence can be understood as a set of individual experiences and skills. The need for skill building will be greater when the level of complexity of the task or of "operational uncertainty" is higher; that is, when the understanding of the causes, effects and 
interdependences among the different parts of a productive process or system are more difficult to identify (Wall, Cordery, \& Clegg, 2002, p. 159).

Competence - as the remaining elements that comprise the Triple Scull Framework - is at the same time a requirement (antecedent) for participation and a consequence of it. Participation has a positive effect on personal development and on the acquisition of cognitive, social, self-regulatory, and also technical competences, whether directly related to the function of the individual or not (Wilpert, 1998). On the other hand, someone's ideas and initiatives will only be effective if competences are previously developed. In the absence of a minimum level of experience and skills, any work situation that gives voice and autonomy to individuals carries a high risk of making contributions insignificant, or even becoming a space for "non-authentic" participation, with the sole intention of "simulating" higher levels of engagement and participation (Heller, 1998b, p. 153). The principle that should guide the adoption of participative solutions was called "skill match" by Frank Heller (Wilpert, 1998, p. 46), meaning a convenient balance between skills and experiences, and the complexity of attributions and responsibilities required by participative practices.

\section{Motivation}

Skill match itself already represents a drive in the direction of greater motivation. Excessively simple or excessively complex tasks lead individuals, respectively, to boredom or to high levels of anxiety (Ulrich, 1997). A convenient definition of challenge and achievement in terms of work content - and of responsibility, growth and the recognition associated to them - is a powerful motivational leverage, a fact widely acknowledged as from the works of Herzberg (1968) and more recently reinforced by Amabile and Kramer (2011). Then, when thinking about engaging and enabling people, a balance of the competences offered by individuals and those required by their work or their superiors is absolutely essential. Ideally, when the content of work allows not only the use, but also the significant development of skills, the level of difficulty of tasks or of participation in improvements and problem solving should have moderate and gradual changes, because individuals tend to react negatively when exposed to major leaps in their levels of autonomy and responsibility (Heller, 1998a).

This first set of two key elements (the first line of oars in the scull boat) - competences and motivation - operates basically at the individual level, and when conveniently weighed, comprises double interaction dynamics, a virtuous circle that may lead to successive cycles of learning through the development of skills to execute the task, and also skills to act in improvement and problemsolving activities and, consequently, leading to new levels of performance. The managerial role is essential for building this weighting or balance. In this field in particular, as underscored by Pfeffer, what is true is more important than what is new (Pfeffer \& Sutton, 2006): the guidance for successful managerial action were very well detailed in the model developed and improved by Hersey, Blanchard and Johnson (2000, p. 189). Competences and motivation, named by them as "skills and will", should be worked to take individuals to a state of readiness, and it is the role of the manager to read the situation in terms of competences brought on by his/her subordinates, their level of motivation or will, and the complexity of tasks. The levels of individual autonomy and contribution should be greater when the skills and motivation of specific subordinates are also greater.

\section{Technology}

Along the 20th century, the increase in the market and organization complexity transformed the predominance of manufacturing work into clerical and service functions. At the same time, technological development transformed manufacturing work though mechanization and automation, while clerical and service activities have been strongly modified by automation and computerization. In the manufacturing environment, the growing automation ultimately transferred product processing to automatic machines and transformed workers into system controllers (Kern \& Schulmann, 1992).

In this scenario, automation led to a reconfiguration of roles and more autonomous and complex activities by workers, who then became responsible for maneuvers, equipment reconfigurations, and 
order sequencing, which freed engineers and managers to test new products and processes (Hirschhorn, Noble, \& Rankin, 2001). Strongly automated environments demand high levels of skills and experience from operators, under the risk of compromising the performance of the production system as a whole. As pointed out before by Adler (1992, p. 5), "the absence of skills, rather than the excess of skills, has proven to be the most commonly found hurdle in automation projects". More recently, Adler and Chen (2011) found that control systems are compatible with creativity and intrinsic motivation.

In functions related to non-manufacturing activities, typically clerical processes, service rendering, consulting, and the full range of tasks that fit into the concept of knowledge work (Drucker, 1999), not only automation, but mainly information technology has been the variable with the greatest impact on organization alternatives and the forms in which individuals can contribute or participate in decision making. Particularly, lowering communication costs are feeding many people with enough information to make decisions by themselves, generating quality decisions, creativity and flexibility (Malone, 2004).

The intensive use of information technology has not only permitted companies to develop new forms of generating ideas and alternatives for problem solving and decision making, but has also allowed the emergence of new businesses and new ways of collecting and coordinating the contributions of different people. It has also opened the possibility for these contributions to come not only from employees, but also from customers and members of their communities, in processes built by collective intelligence (Malone, 2004) or crowdsourcing (Liberty \& Spector, 2009). Although these are very recent phenomena - based on the conclusions of Thomas Malone - it is already possible to say that the success in the intensive use of information technology to involve people in innovations, improvements, and decision making relies on the same individual levers that support performance in any form of organization and participation: motivation and competences.

Different types of production processes, in a way that is very independent from the issue of automation or the use of information technology, also carry different levels of uncertainties, instabilities, intensities of unpredictable events, and, consequently, opportunities for standardizations and task prescription. The nature of a production system can limit the feasibility of participation and organization choices (Trist, 1981) must be made in order to reach a kind of joint-optimization (Heller, 2001). For instance, flow production systems (like automobile assembly lines) generate necessarily limited and repetitive tasks, limiting the forms through which workers can contribute and solve problems. On the other hand, continuous processing technologies, as in the chemical and pulp \& paper industries, with high occurrence of events and instabilities, demand an intensification of the interaction between operators and an integration and inter-relationship between tasks.

The kind and the intensity of mechanization, automation and computerization in a given production process of goods, services or information will strongly determine the intrinsic characteristics of employees' tasks, with impact on performance and motivation. Technology emerges, in short, as a variable that enables or hinders different forms of contribution and participation. The understanding of its nature or characteristics is then essential for different Work \& Participation Practices to be consistently chosen and permit the best possible use of individual contributions and a greater will for engagement by these same individuals.

\section{Culture}

"Culture influences the company's way of being and doing things... cultural practices can guide and uphold the development of certain competences in detriment of others" (Fleury, 2009, p. 12). Innovation, adaptation capacity, and survival in dynamic environments call for creativity, speed and quality in answers and solutions. These, in turn, depend on the engagement, collaboration and integration between the members that form teams, in addition to a high level of trust between them, managers, and the organization. This calls for free communication, the possibility of making mistakes, transparence in objectives and purposes, the pursuit of consensus, influence based on technical 
competence and on knowledge, and the acceptance of the inevitable conflicts in dealing with change and innovation. In short, as authors like Likert and Bennis said around 50 years ago, individual participation and contribution need to be nourished by democratic values to produce results and differentiated performance (Likert, 1961; Slater \& Bennis, 1964). These democratic values, translated into common operation assumptions and principles - involving workers and managers - are fundamental for innovations to survive and proliferate (Schein, 1996).

Another component of the organizational culture that is fundamental for the engagement of individuals is an unmistakable consistence of purposes and attitudes in the long term, which encompasses a commitment, without exceptions, with established and agreed-upon rules (Galford \& Drapeau, 2003). This consistence also emanates from an objectivist ethics stand of the managers (Locke, 2006). Managers' behaviors should always show a sense of justice, a veracity of what is said, keeping agreements and promises and respecting individuals - their intrinsic value and their contributions to the organization (Clawson, 2009). It is also important that consistence occurs across all managerial layers (O’Reilly, Caldwell, Chatman, Lapiz, \& Self, 2010).

And this consistence leads to a connection with a last but essential element that enables and involves people: trust. "Trust is a belief, security, and positive expectation that emerges inside a community in which behaviors are regular, honest and collaborative - based on rules shared by the members of that community" (Fukuyama, 1995, p. 26). "Companies can't innovate, respond to changing stakeholder needs, or function efficiently unless people have access to relevant, timely and valid information. It's thus the leader's job to create systems and norms that lead to a culture of candor" (O'Toole \& Bennis, 2009, p. 56). It only develops in a reciprocal way, through personal contacts and by knowing the other - which means that forms of distant collaboration, supported by information technology, usually require a high level of trust (Heller, 1998b). It blossoms through a virtuous circle in which the organization, managers and/or colleagues show to be worthy of trust, and those who, in turn, start to trust them due to their proofs of delivery capacity and contribution. Higher levels of trust mean greater capacity for managers to give autonomy and delegate power and, in this manner, limit control actions.

\section{Human resources policies}

People management in organizations has been faced with an important transformation in the formal bonds between the company and its employees. Work relations have been getting increasingly more flexible. The employees of an organization are not just regular full-time employees, but also temporary workers, part-time workers, contracted employees, and free-lance workers. Everyone can work side-by-side on important tasks and functions that require intense interaction and engagement. To support a culture of trust and collaboration, human resource policies must consider this diversity and minimize differences and avoidable barriers, allowing motivation, sense of belonging, and competence development to reach everybody regardless the type of bond. These policies can reinforce participative behaviors and lead to growing engagement and more autonomous and collaborative work. They have demonstrated a significant synergy with participative practices.

The main people management themes with effective capacity to cause an impact on the levels of competence and motivation of individuals and teams are: (a) stability and profound respect in the relationships between the company and its employees (Pfeffer, 2010; Sutton, 2009); (b) an egalitarian, or with minimal difference, treatment for full employees and workers with other types of employment ties; (c) higher levels of compensation than in organizations that do not adopt participative practices, because employees expect to be rewarded and recognized for better financial results. In this manner, compensation should depend on performance (Pfeffer, 1998); (d) profit-sharing programs and bonuses based on group performance (Levine \& Tyson, 1990); (e) selectivity in recruiting, focusing on necessary competences and considering that in participative environments, individuals must be previously endowed with minimal competences to reach a satisfactory performance (Pfeffer, 1998). Moreover, hires must have the "cultural fit" as a main criteria (Baron \& Kreps, 1999, p. 190); (f) competence development and balancing - through on-the-job training, job rotation and other 
modalities - thus making employees reach the levels of capacity necessary for participative practices. In this case, as well as in the item before, the ideal is to seek the aforementioned skill match. This usually implies significant investments allocated to qualification (Strauss, 1998) (greater details for the development of competences can be found in the work of Heller, 2003; Pfeffer, 1998 and Sydänmaanlakka, 2002); (g) minimization of wage differences and status symbols (Levine \& Tyson, 1990; Pfeffer, 2010); and (h) guarantees of individual rights, so as to ensure to people that they will not be punished for participation (Levine \& Tyson, 1990) and that they will not be bullied by managers with improper attitudes (Sutton, 2007). "Bosses who ignore and stomp on their subordinates' humanity sometimes generate quick gains. But in the long run, such shortsightedness undermines creativity, efficiency and commitment" (Sutton, 2010, p. 95).

A ninth theme that must comprise this set of policies and practices pertains to managerial capacity-building and development. Supervisors, managers and executive officers also need training and capacity-building to deal with situations related to power sharing and greater delegation and autonomy. A usual reaction managers have when more collaborative and participative work environments are established is the feeling of threat and loss of control and power (Heller, 1998b). A tenth and last theme is related to the empowerment of managers themselves: empowering leadership has a positive correlation with knowledge sharing and team efficacy (Srivastava, Bartol, \& Locke, 2006).

Coping with uncertainties, being able to listen, learning participation and engagement techniques and tools, reducing the drive to control, gaining capacity to orient and delegate are some of the competences that need to be developed by managers in the many levels of the hierarchical structure. As highlighted by Drucker (1999), the productivity of knowledge workers who can make specific contributions with high intellectual content is the great challenge that Administration has to face in the $21^{\text {st }}$ century. More than directing and controlling, managers need to understand how their subordinates and themselves learn, which are their values, which are the contributions their subordinates can make, which results they can deliver, and which organization and participation tools they can use to leverage the contributions of all.

\section{Work \& Participation Practices}

Among the elements that comprise the Triple Scull framework, Work \& Participation Practices stand out because it is through them that work and individual/team contributions happen. Work \& Participation Practices encompass the organizational arrangements and solutions that allow individuals - to some extent - to contribute and influence in a discretionary and critical way, using their intellectual capacities, relationship skills, and experience toward innovation, problem-solving and decision making. In this manner, they enable some personal impact in terms of the content, format or result of their more immediate work, the activities of their group, even extending beyond the organization as a whole. They are called work and participation because they comprehend both work organization arrangements - that is, when contribution opportunities emerge during tasks directly related to functions - and off-line contribution opportunities - that is, activities complementary to those intrinsically related to the organization of tasks.

Understanding the nature and the significant differences between the many Work \& Participation Practices comes by the utilization of two key dimensions. The first of them was already addressed when we talked about technology and processes. The way technology is adopted not only determines what will be made by the machines, computers and systems, but also the way people connect, interact and collaborate. The essential dimension presented here is intellectual capital, located in the Locus of Knowledge.

For the practical purpose of building the conceptual model developed by the author, the taxonomy proposed here will consider two components of knowledge/intellectual capital: (a) practices 
in which people are the predominant Locus of Knowledge, that is, activities and forms of work in which there may be tools (physical or analytical/conceptual), equipment, and systems used in the tasks, but the most important and effective contributions depend on the intelligence and experience of individuals and their relational networks, and (b) practices in which the most important part of knowledge, based on the organization's orientation and investments, is incorporated in routines, machines, and computers, that is, practices in which the Locus of Knowledge lies predominantly in processes, systems and equipments. In relation to a classification adopted by Kang and Snell (2009, p. 68), the first component embraces the categories of "human" and "social" knowledge/intellectual capital and the second one the "organizational" Knowledge/intellectual capital.

The second key dimension for understanding the nature of Work \& Participation Practices is related to decision power. Individuals' participation and contribution capacities are either directly attached to the existing space for minimally autonomous work or negotiated between workers and managers. The decision power, or the level of influence in the decision-making process, is an essential condition to "ensure the interests or contribute toward the choice process", as in Wilpert's (1998, p. 42) definition of participation. Different participation approaches come into being when managers no longer decide unilaterally about a given theme, but rather subordinates start to have room for influence or even for participation in decision making at different degrees. The importance of the decisionsharing degree shows in the prominence it gains in some of the most renowned conceptual references - Tannenbaum and Schmidt (1958), Likert (1961), and Hersey, Blanchard and Johnson (2000) - and also in the main reviews found in the literature - Cotton, Vollrath, Frogratt, Lengnick-Hall, and Jennings (1988), Locke and Schweiger (1990), Levine and Tyson (1990), and Heller, Pusic, Strauss, and Wilpert (1998).

In this manner, the second key dimension is the Locus of Power, and for the construction of our taxonomy, we will adopt two types of work and participation arrangements whose concepts are based on those developed by Levine and Tyson (1990): consultative participation and substantive participation. Consultative participation is that which allows employees to give their opinions, but final decisions are still made by managers. The initiatives, ideas, and proposals generated by employees must be validated by the immediate superior or a group of managers or specialists. In these circumstances, workers can identify problems, generate alternatives or even make recommendations about issues not directly related to their most immediate attributions, but will always need to have their contributions validated by managers.

On the other hand, substantive participation is that in which Work \& Participation Practices imply effective power sharing. The issues or problems may even be similar to those of consultative participation, but in this case, through formal or at least institutionalized mechanisms, employees are involved in a clear and significant manner in decision making. The decision power, in this second case, is not concentrated just in managers, but is distributed, giving a voice to employees. Managers never give up $100 \%$ of their decision power, because even omission or complete delegation are still evidences that they hold power. In practice, similarly to the definitions related to the Locus of Knowledge, we adopt two possibilities in the case of the dimension Locus of Power: (a) consultative participation, in which largely managerial decisions prevail; and (b) substantive participation, in which the decision power is clearly shared by the group as a whole and the manager, although usually entitled to participate in decisions, cannot make them alone. Based on these two dimensions - locus of knowledge and locus of power - and their alternatives - knowledge concentrated in processes/systems vs. knowledge concentrated in people, and consultative participation vs. substantive participation - we arrive at four basic types of Work \& Participation Practices (Figure 2). The Dril Matrix, developed by the author, presents a taxonomy of Work \& Participation Practices based on the dimensions of Locus of Knowledge and Locus of Power. The word dril is an acronym with the initials of the four different types of practices. 


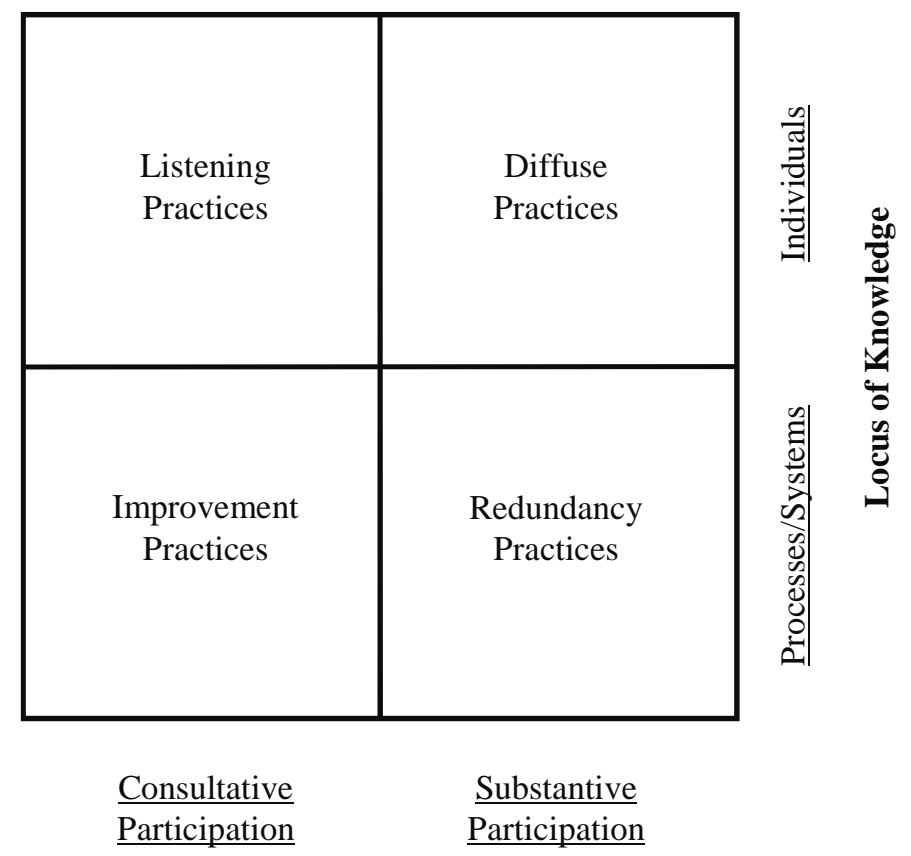

Locus of Power

Figure 2. The Dril Matrix.

Source: Elaborated by the author.

\section{Improvement practices}

In this referential, these are the Work \& Participation Practices in which the decision power lies in the hands of managers, and that take place in the work situations in which a set of activities have been extensively studied, detailed, understood, and translated into procedures, equipment, and information systems. In these circumstances, contributions are made through practices and tools in which the scope and form of employee participation are quite well-defined and detailed, giving margin to contributions usually very focused on issues more closely related to the work of these individuals and permitting small advances and gains in terms of productivity and quality in already very wellestablished processes.

Although not limited to them, the main example of this type of practice are the arrangements developed by the Japanese, particularly Toyota between the 50's and 70's, and which resulted in TQM and Lean Production models. From this source we may highlight, for example, warning devices for assembly problems connected to information panels (Andons), through which any worker can momentarily stop the line and be helped by colleagues and supervisor, who will decide whether to effectively stop or implement another solution based on what they hear from the operator who rang the alarm and his/her colleagues. Control quality circles, the 5Ss technique and the Ringi system (Wickens, 1995) also fit into improvement practices.

Other Improvement Practices emerged from the application of job enrichment developed by Herzberg (1968), according to which some task controls are removed for operators to take on more responsibility for their work and their own performance. The master and apprentice dynamics that originated in Germany (Appelbaum \& Batt, 1994; Fukuyama, 1995) can also be considered as sources of improvement practices. But such practices do not necessarily need to be attached to any of the former examples. A simple meeting of operators at the end of a shift in a service center for reporting/debating occurrences, and receive orientation from the supervisor can be considered an improvement practice. 


\section{Listening practices}

These are the practices that also keep the decision power in the hands of managers, but that occur in work situations in which the knowledge and the development of activities strongly depend on the intelligence and initiative of the individuals involved - even if for the execution of their work they have the support of equipment or information technology. In these circumstances, contributions can be made through suggestions, recommendations, and individual or collective initiatives. These practices can be established informally, in the every-day interaction between employees, their colleagues and superiors, but the final decision will always be made by the manager. Individuals can take the initiative of proposing an idea for a given issue or even managers can make room for the contributions of their subordinates by consulting them individually or collectively. Managers can present a problem or propose a solution, which can then be complemented and enriched with the suggestions of subordinates, in an equivalent manner to the intermediate levels of the leader behavior continuum developed long ago by Tannenbaum and Schmidt (1958).

But Listening Practices can also be formal and institutionalized. In this case, perhaps the most widely known example are the Work-Out sessions developed and disseminated by GE. Work-Out is a practice in which small groups of managers and employees, multifunctional, multilevel or both, address fundamental issues, develop recommendations and present them to a senior leader in a general meeting. After an open conversation, the leader immediately makes decisions of the type yes or no in relation to such recommendations, transfers powers to people for them to execute the recommendations approved, and then regularly analyzes progress to make sure results are attained (Ulrich, Kerr, \& Ashkenas, 2002).

Another interesting example was created by HP to define project themes and teams: (a) people present ideas and themes for projects and senior managers choose the projects that will be sponsored, (b) projects are disseminated and employees apply for those they would like to work in and (c) project leaders build their teams selecting members from those who applied (Malone, 2004).

In the field of crowdsourcing, the development of Linux can be considered an example of a Listening Practice, because all voluntary contributions from its developers have to be approved by a committee structured by Linus Torsvald. Another successful examples of the adoption of loosely connected collective intelligence groups can be seen in Google, Wikipedia and Threadless (Malone, Laubacher, \& Dellarocas, 2010).

\section{Redundancy practices}

This type of practice, similar to the improvement type, happens in activities that are extensively studied, in which there is a pursuit for predictability and possible anticipation of events. The knowledge about functions is strongly transferred to equipment, monitoring, and control systems. But different from Improvement Practices, Redundancy Practices happen in decision processes that also allow workers a high level of discretion, with capacity for intervention and making decisions that are frequently made without direct intervention from management. An immediate consequence of the adoption of this type of practice is that they have higher implementation and operation costs than other types of Work \& Participation Practices. In this case, the option is to invest in processes and making them automatic, predictable, reliable and, at the same time, to compensate more qualified people and train them so they can intervene and act in an autonomous way, using their skills and experience whenever they judge convenient or necessary.

The most representative organizational arrangement of Redundancy Practices are the so-called semi-autonomous groups, that originated from studies at coal mines conducted by researchers from the Tavistock Institute around 1950 (Trist, 1981). They are organized based on principles called sociotechnical and are characterized by the participation of workers in the definition of tasks and work methods, being "collectively responsible for a substantial and manageable part of the process, with a work arrangement that enables personal relations and cooperative interaction and... authority, 
equipment and materials necessary for the execution of tasks" (Pearce \& Ravlin, 1987, p. 756). This practice initially spread in Norway - in pulp \& paper, fertilizer and steel manufacturing plants (Gustavsen \& Hunnius, 1981) - and in Sweden, particularly at Saab and at Volvo (Auer \& Riegler, 1990). After the 1970's, the semi-autonomous groups were successfully implemented in hundreds of companies, mainly in continuous processing plants (Shani, Grant, Krishnan, \& Thompson, 1992). At Volvo, Redundancy Practices were adopted for social reasons - a highly qualified workforce and a closed work market - but its adoption began to be questioned with market opening, transfer of production units to other countries like Belgium, and the joint-venture with Renault.

The convenience of this kind of arrangement for this type of potentially hazardous plants nuclear, pulp \& paper, chemical \& oil, and steel - is related not only to the absence of clear frontiers between functions, but mainly to the need to control and anticipate events that might result not only in loss of momentary performance, but in accidents with potentially catastrophic consequences. That why it makes sense to invest heavily in automation and process computerization, and, at the same time count on highly qualified autonomous personnel with the capacity to make quickly decisions and intervene (Wilpert, 2008a, 2008b). A similar logic applies to small crews of the most modern Boeing, Embraer and Airbus aircrafts, supported by sophisticated redundant flight control systems, but still capable of intervening at any moment, within the parameters established in these same systems.

\section{Diffuse practices}

The last type of Work \& Participation Practice is characterized by significant power sharing, both for conducting activities in a quite autonomous manner and in the distribution of decision power. And also by a clear dependence on the capacities, initiatives and interaction of those involved in tasks. Even if informally or non-structured, these types of arrangement occur in research centers, universities, consulting, and other professional services' offices. Nevertheless, they can still be found - and developed - in a wide range of organizations.

Due to decision sharing, these practices are necessarily related to decentralization, autonomy and pursuit for consensus involving not only the members of a team, but also their managers. Organizational arrangements contemplating shared decisions and pursuing consensus were already suggested in the 1960's - by authors like Likert (1961) and Slater and Bennis (1964). In the late 1970's, Frederick and Merrelyn Emery developed the concept of participative projects - involving representatives of several levels of the organization, duly skilled to be able to generate proposals without the support of consultants - and the concept of search conferences - in which scenarios for the organization should be discussed and planning guidelines should be laid out in large plenary sessions, involving up to hundreds of people of all areas and levels of the company (Emery, 1982). More recent reports of the utilization of these concepts at Microsoft and Motorola were given by Purser and Cabana (1998).

Another Diffuse Practice - named scrum - is an arrangement for the development of new products in which self-organized project teams conduct development phases partially overlapped in time. These teams begin from guidelines with little detail, work in a very interactive way, and are obliged to keep in contact with the remaining sub-groups and external sources of information, learning in a multidisciplinary manner throughout the process. The scrum process was first observed in companies like Canon, Fuji-Xerox, NEC and Honda. "Management establishes some checkpoints to prevent instability, ambiguity and tension from becoming chaos. At the same time, managers avoid rigid control forms that could block creativity and spontaneity" (Takeuchi \& Nonaka, 1986, p. 86). The complex interactions and interdependencies inside this and other kinds of teamwork arrangements have been better understood through a "network perspective", as developed by Cross, Ehrlich, Dawson and Helferich (2008).

At AES there is an extreme delegation practice, consisting of the possibility that any employee can make a decision or take initiative, so long as he/she has asked and received advice from several people in the organization. Managers work primarily as advisors and guardians of AES' principles and 
values. With this way of working, the company has built many business cases, like the employee who bought a power generation plant in England after having worked at AES for only two years. He had the idea and sought advice, mainly by e-mail, from dozens of people in many positions and areas in AES (Malone, 2004, pp. 47-51).

The examples given of this and other types of Work \& Participation Practices do not intend to be comprehensive, but to show the most significant and representative cases of each one of the types. Considering the development of the present text from its beginning, an initial issue was proposed: how to improve organizational effectiveness through individuals and groups, that is, how to make the most of and leverage the contributions of all, profiting from the engagement, initiatives and capacities of each individual in the organization. As the first part of the answer, the Triple Scull Framework was proposed, underscoring 3 sub-sets of essential elements for the task: (a) individual competences and motivations, (b) Human Resource Policies and Work \& Participation Practices; and (c) cultural and technological bases that will guide these policies and practices. The second part of the answer comes through a conceptual reference of Work \& Organization Practices, identifying 4 types of these practices based on their basic dimensions: Locus of Knowledge and Locus of Power (Figure 3). The last part of the answer comes in the following section, in which the guidelines to adopt different types of Work \& Participation Practices are summarized, trying to highlight in which situations each one of them is more likely to succeed.

\begin{tabular}{|c|c|c|}
\hline $\begin{array}{c}\text { GE Work-out } \\
\text { HP Project Teams } \\
\text { Linux Development }\end{array}$ & $\begin{array}{c}\text { Canon Scrum } \\
\text { AES Delegation } \\
\text { Search Conferences }\end{array}$ \\
(Listening Practices) & (Diffuse Practices) & \\
\hline $\begin{array}{c}\text { Quality Circles } \\
\text { Toyota Line Stops } \\
\text { Job Enrichment }\end{array}$ & $\begin{array}{c}\text { Semi-autonomous } \\
\text { Working Groups }\end{array}$ \\
Aircraft Crew Teams & (Redundancy Practices) \\
(Improvement Practices) & $\underline{\text { Substantive }}$ \\
$\underline{\text { Participation }}$ &
\end{tabular}

\section{Locus of Power}

Figure 3. Main Examples of Work and Participation Practices.

Source: Elaborated by the author.

\section{Final Propositions - Balancing the Elements of the "Triple Scull"}

Almost as strong as the evidence that participative arrangements and practices can cause much more positive impacts for the people and organizations are the evidences that these practices only succeed in certain situations. As summarized by Strauss (2006, p. 799), for participation work, "conditions have to be appropriate". There is a complex dynamic between Work \& Participation Practices and the context in which they are adopted, which then requires a systemic approach (Heller, 2003). The Triple Scull Framework is a model which tries to highlight the essential elements to be dynamically harmonized and adjusted for by different practices to effectively give voice, means and opportunities for significant contributions, and consequently support organizational renewal. Certainly 
this harmonization, alignment and detailing exercise can and must be refined and furthered in future studies and papers.

For the summaries that follow, some reference sources were used. Although they started from different models and perspectives, they served so that the entire array possibilities in terms of different values, competences, managerial behaviors, and people management practices could be retrieved, categorized and summarized by the author in the model proposed. These main sources were the works of Heller et al. (1998), Sisson and Storey (2000), Hersey, Blanchard and Johnson (2000), and Clawson (2009).

The first element that needs to be considered is technology and the overall characteristics of the organizations that have usually adopted the different types of practices. Improvement Practices are usually found in organizations that have flow processes, like the large-scale assembly of cars or electro-electronic products, with intense emphasis on quality and cost, characterized by a traditional hierarchical structure and vertical information flows. They are conditions that may also be found in service companies like, for example, call centers. Redundancy Practices are more frequent in capitalintensive continuous processing facilities, with strong emphasis on risk minimization and intense lateral communication flows. Diffuse Practices, in contrast, are predominantly found in companies intensive in human capital, with emphasis on differentiation and innovation, that are more decentralized and less hierarchical, with network information flows. Last, although the most widely known Listening Practices were developed in organizations like GE - that are high tech, diversified and compete through the differentiation of their products and services - they are characterized by not presenting too many contingency ties, and can be adopted in technology and business contexts that are comparatively broader than the other types of practices. This characteristic will recur when we seek the alignment of the other elements.

When we focus on organizational culture, above all, it is necessary to stress that trust atmosphere and relationships, along with the acceptance of democratic principles, are the basis for adopting any initiative aimed at higher levels of engagement and contribution by the members of an organization. On the other hand, there seems to be some specific emphases more closely related to each type of practice, as shown in Figure 4.

\begin{tabular}{|c|c|}
\hline $\begin{array}{c}\text { No specific set of values, } \\
\text { but sharing with the } \\
\text { other quadrants basic } \\
\text { attitudes of respect, } \\
\text { collaboration, } \\
\text { consistency and trust } \\
\text { (Listening Practices) }\end{array}$ & $\begin{array}{c}\text { Continuous learning } \\
\text { Product orientation } \\
\text { Inquisitive posture } \\
\text { Information sharing } \\
\text { Flexibility }\end{array}$ \\
\hline Continuous & (Diffuse Practices) \\
improvement & Predictability \\
Quality/cost orientation & Process orientation \\
Padronization & Cooperation \\
Discipline & Mutual support \\
Reliability & (Redundancy Practices) \\
(Improvement Practices) & (2)
\end{tabular}

\section{Consultative Substantive \\ $\underline{\text { Participation }}$ Participation}

\section{Locus of Power}

Figure 4. A Variant of the Dril Matrix Highlighting Organizational Values and Cultural Characteristics to Be Shared Among Workers and Managers in Each Type of Work \& Participation Practice.

Source: Elaborated by the author. 
Conversely, when we focus on motivation, the most important consideration is to see that Work \& Participation Practices themselves and their dynamic interaction with Human Resources Policies will be the main drivers of individual and team motivation, in all cases providing reinforcement in terms of realization, recognition, and responsibility appropriate to each individual's level of competence. In the case of competences, it seems possible and desirable to define which sets are more attached to each type of practice, as presented in Figure 5.

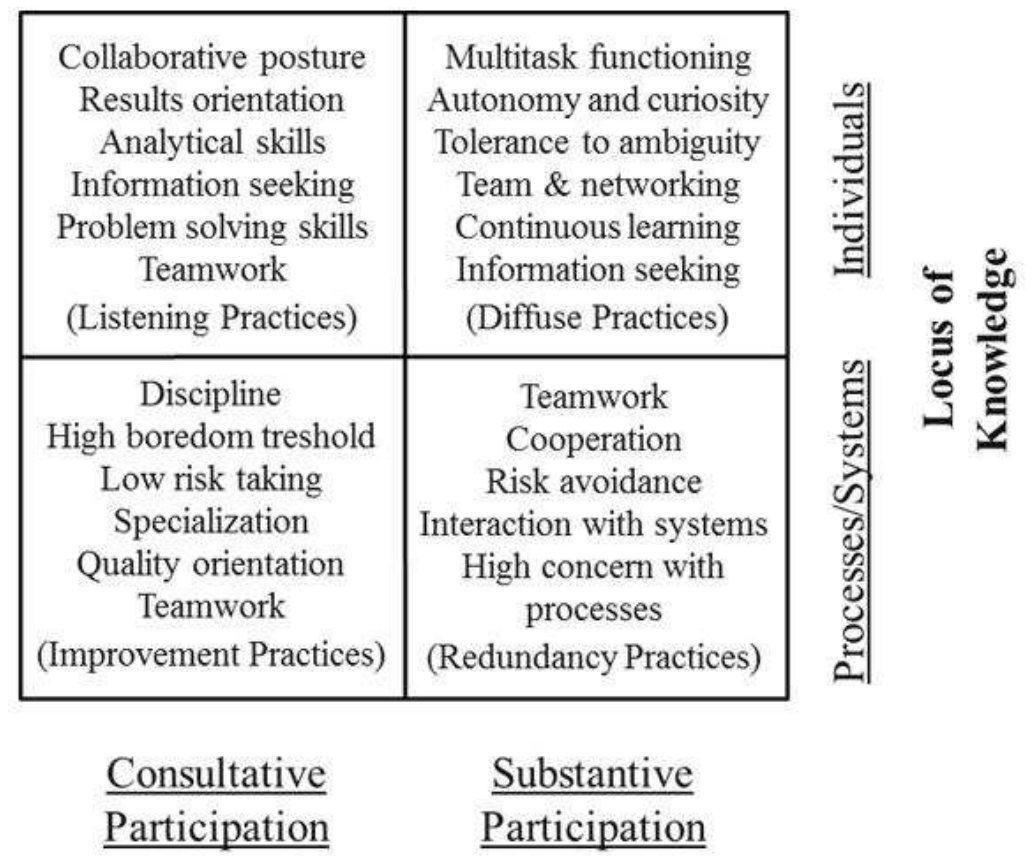

\section{Locus of Power}

Figure 5. A Variant of the Dril Matrix Highlighting the Most Important Competences Demanded from Workers in Each Type of Work \& Participation Practice.

Source: Elaborated by the author.

In relation to the managerial competences in each case, we may say that Improvement Practices demand more directive managers, widely using the power of their position in orders and commands and for the determination of objectives and times. For Redundancy Practices, the emphasis lies on the manager's ability to provide support, monitor at a distance without the concern of interfering, taking care, serving, and providing the resources and conditions for their subordinates' work through their connection power in the organization. To conduct Listening Practices, on the other hand, managers will predominantly use their expertise in the organization's problems and workings to orient their analyses, arguments, explanations, and decisions. Lastly, Diffuse Practices require managers to focus their work on their reference power as a role model, in addition to their capacity for facilitation and creation of environments conducive to collaboration and high interaction between team members.

It is also fundamental that Human Resource Policies be aligned with Work \& Participation Practices and be efficient for the development of the specific set of competences of workers and managers in each case. In addition to the alignment with Work \& Participation Practices, Human Resources Policies - training, compensation, job description, career paths, and others - need to show consistency between themselves (Figure 6). A later development or future work could focus specifically on detailing the different Human Resource Policies necessary for each type of Work \& Participation Practice proposed in the Dril matrix. 


\begin{tabular}{|c|c|c|}
\hline $\begin{array}{l}\text { No specific types } \\
\text { of job descriptions, } \\
\text { compensation models, } \\
\text { carreer paths, } \\
\text { appraisal criteria } \\
\text { or other HR policies }\end{array}$ & $\begin{array}{c}\text { Loosely defined jobs } \\
\text { Focused on internal equity } \\
\text { High use of variable pay } \\
\text { Lateral/vertical career paths } \\
\text { Extensive training } \\
\text { Long-term indiv./group } \\
\text { criteria for appraisal }\end{array}$ & 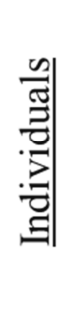 \\
\hline $\begin{array}{l}\text { Narrowly defined jobs } \\
\text { Close monitoring of labor } \\
\text { market pay levels } \\
\text { Short term results } \\
\text { performance appraisal } \\
\text { Restricted/focused training } \\
\text { Vertical career paths } \\
\text { Internal labor market } \\
\end{array}$ & \begin{tabular}{|c|} 
Broadly defined jobs \\
Egalitarian compensation \\
Job security efforts \\
Few carreer steps based \\
on competences \\
Multifunctional training \\
Individual and group \\
criteria for appraisal \\
\end{tabular} & 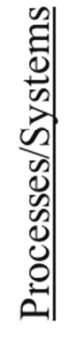 \\
\hline$\frac{\text { Consultative }}{\underline{\text { Participation }}}$ & $\frac{\text { Substantive }}{\text { Participation }}$ & \\
\hline
\end{tabular}

\section{Locus of Power}

Figure 6. A Variant of the Dril Matrix Highlighting Guidelines for Designing Human Resources Policies in Alignment with Respective Types of Work \& Participation Practices.

Source: Elaborated by the author.

A final but crucial consideration is related to how to conciliate the frameworks and arguments proposed in this article with the compelling evidences that, in order to adapt and survive, an organization can face a portfolio of "current core business, growth business, and future growth business - with each type of business having unique challenges and requiring a different organizational architecture" (O'Reilly, Harreld \& Tushman, 2009, p. 86)? How to, at the same time, pursue cost, efficiency and incremental innovation demanded by mature business with learning, adaptation and risk taking demanded by future ones? O'Reilly and Tushman (2011) state that this ambidexterity will succeed if - although sharing values - an organization builds "separate but aligned organizational architectures (business models, structure, incentives, metrics and cultures) for the exploratory and exploitative units" (p. 9). It implies that, if an organization has a strategic insight that simultaneously embraces exploitation and exploration, its respective units or parts - accountable for mature or new business - must be set accordingly. Bringing this argumentation to the conceptual referential developed in this paper, it is coherent to state that different quadrants of the Dril Matrix can and should be adopted by the same organization, at the same time. For exploitative business, improvement and redundancy practices appear to be more appropriate, while diffuse practices appears to be the best choice for exploratory business. Listening practices seems to be adopted in both cases. Following the proposition that it is necessary to align the elements of the Triple Scull Framework, the logical consequence is that just one scull may not be enough. An ambidextrous organization will succeed if its exploratory and exploitative units are consistently arranged in terms of the Triple Scull Framework elements (competences, motivation, Work \& Participation Practices, Human Resource Policies, Culture and Technological background). It means that there will be two different sculls - one for exploratory units and another one for exploitative units - each one internally consistent but different between themselves (partially overlapped at most), pursuing different strategic insight goals but sharing common essential values and the same overall direction for the whole organization.

Although obviously calling for improvements, detailing, and ratification in further researches and studies, the herein presented conceptual frameworks and propositions - based on the understanding of the underlying structuring logic and the assumptions that support each type of Work \& Participation Practice - provide opportunities for: (a) enabling the understanding of the impact of these practices on individuals and organizations, in arrangements and organizations that prevailed 
along the $20^{\text {th }}$ century, and in the organizations and businesses of the post-industrial age, particularly the new businesses and organizations based on the Internet and on the intensive use of information technology; (b) expanding the adoption of the aforementioned and partly already "renowned" Work \& Participation Practices; (c) promoting in each case of adoption the alignment of the elements that comprise the Triple Scull Framework and, in this manner, increase the chances of success and the impact of such adoptions; (d) encouraging and inspiring the creation of new practices; and also (e) opening a new perspective and new reflections about the successful development of ambidextrous organizations and organizational renewal.

There is wide evidence that power is excessively concentrated at higher hierarchical levels of organizations and workers long for more participation and influence (Heller, Pusic, Strauss, \& Wilpert, 1998). In spite of a typical discourse among executive officers, "there is little evidence of experimentation with new forms of participation" (Strauss, 2006, p. 800). It is surprising that this is the case although organizations need increasingly more to make the best use of individuals' initiatives and capacities in order to evolve and survive in the long run. The key question is not must or must not organizations adopt practices that allow greater participation and influence of their employees?". The question is "how to do it?".

\section{Received 20 October 2011; received in revised form 21 March 2012.}

\section{Acknowledgements}

The author would like to acknowledge the invaluable guidance, enlightenment and support given by Afonso Fleury (Escola Politécnica, Universidade de São Paulo), and also by Scott Snell (University of Virginia, Darden School of Business) and Frank Heller (The Tavistock Institute, in memoriam). It has been truly an honor and a great privilege to learn with them. Jorge Biazzi (Faculdade de Economia e Administração, Universidade de São Paulo), Ivana Suffredini and Flavia Romano helped me significantly during the processes of review, database research and translation of the paper. Finally, the very substantial and meaningful comments from the journal editor and reviewers also helped me in refining the framework and arguments in this final version. This paper is dedicated to my children, Eleonora and Lorenzo.

\section{References}

Ackoff, R. L. (2006). Why few organizations adopt systems thinking. Systems Research and Behavioral Science, 23(5), 705-708. doi: 10.1002/sres.791

Adler, P. S. (1992). Technology and the future of work. New York: Oxford University Press.

Adler, P. S., \& Chen, C. X. (2011). Combining creativity and control: understanding individual motivation in large-scale collaborative creativity. Accounting, Organizations \& Society, 36(2), 63-85. doi: doi.org/10.1016/j.aos.2011.02.002

Adler, P. S., Heckscher, C., \& Prusak, L. (2011). Building a collaborative enterprise. Harvard Business Review, 89(7/8), 94-101.

Amabile, T. M., \& Kramer, S. J. (2011). The power of small wins. Harvard Business Review, 89(5), 70-80.

Appelbaum, E., \& Batt, R. (1994). The new American workplace: transforming work systems in the United States. Ithaca: ILR Press \& Cornell University Press.

Auer, P., \& Riegler, C. (1990). Post-Taylorism: the enterprise as a place of learning organizational change. Stockholm: The Swedish Work Environment Fund. 
Baron, J. N., \& Kreps, D. M. (1999). Strategic human resources: frameworks for general managers. Hoboken: John Wiley \& Sons.

Clawson, J. G. (2009). Level three leadership: getting below the surface. New Jersey: Pearson Prentice Hall.

Cotton J. L., Vollrath, D. A., Frogratt, K. L., Lengnick-Hall, M. L., \& Jennings, K. R. (1988). Employee participation: diverse forms and different outcomes. Academy of Management Review, 13(1), 8-22. doi: 10.5465/AMR.1988.4306768

Cross, R., Ehrilch, K., Dawson, R., \& Helferich, J. (2008). Managing collaboration: improving team effectiveness through a network perspective. California Management Review, 50(4), 74-98. doi: 10.1504/WREMSD.2008.018228

Drucker, P. F. (1999). Knowledge worker productivity: the biggest challenge. California Management Review, 41(2), 79-94.

Emery, F. E. (1982). New perspectives in the world of work: sociotechnical foundations for a new social order? Human Relations, 35(12), 1095-1122.

Fleury, M. T. L. (2009). Organizational culture and the renewal of competences. Brazilian Administration Review, 6(1), 1-14. Retrieved from http://www.scielo.br/pdf/bar/v6n1/v6n1a02.pdf. doi: 10.1590/S1807-76922009000100002

Fukuyama, F. (1995). Trust: the social virtues and the creation of prosperity. New York: Free Press.

Galford, R., \& Drapeau A. (2003). The enemies of trust. Harvard Business Review, 81(2), 88-95.

Gustavsen, B., \& Hunnius, G. (1981). New patterns of work reform: the case of norway. Oslo: Universitetsforlaget.

Harreld, J. B., O'Reilly, C. A. III, \& Tushman M. L. (2007). Dynamic capabilities at ibm: driving strategy into action. California Management Review, 49(4), 21-43.

Heller, F. (1998a). Influence at work: a 25-year program of research. Human Relations, 51(12), 14251456. doi: $10.1177 / 001872679805101202$

Heller, F. (1998c). Myth and reality: valediction. In F. Heller, E. Pusic, G. Strauss, \& B. Wilpert, Organizational participation: myth and reality (pp. 220-249). Oxford: Oxford University Press.

Heller, F. (1998b). Playing the devil's advocate: limits to influence sharing in theory and practice. In F. Heller, E. Pusic, G. Strauss, \& B. Wilpert, Organizational participation: myth and reality (pp. 144-189). Oxford: Oxford University Press.

Heller, F. (2001). Towards a socio-oecotechnology. Journal of Engineering and Technology Management, 18(3/4), 295-312. doi: 10.1016/S0923-4748(01)00039-X

Heller, F. (2003). A holistic approach to influence sharing and participation in organizations (Tavistock Document). London: Tavistock Institute.

Heller, F., Pusic, E., Strauss, G., \& Wilpert, B. (1998). Organizational participation: myth and reality. Oxford: Oxford University Press.

Hersey, P., Blanchard, K. H., \& Johnson, D. E. (2000). Management of organizational behavior: leading human resources. New Jersey: Prentice-Hall.

Herzberg, F. (1968). One more time: how do you motivate employees? Harvard Business Review, 46(1), 53-62. 
Hirschhorn, L., Noble, P., \& Rankin, T. (2001). Sociotechnical systems in an age of mass customization. Journal of Engineering and Technology Management, 18(3-4), 241-252. doi: $10.1016 / \mathrm{S} 0923-4748(01) 00036-4$

Kang, S.-C., \& Snell, S. A. (2009). Intellectual capital architectures and ambidextrous learning: a framework for human resource management. Journal of Management Studies, 46(1), 65-90. doi: 10.1111/j.1467-6486.2008.00776.x

Kern, H., \& Schumann, M. (1992). New concepts of production and the emergence of the systems controller. In P. S. Adler (Ed.), Technology and the future of work (pp. 111-142). New York: Oxford University Press.

Levine, D. I., \& Tyson, L. D. (1990). Participation, productivity and the firm's environment. In A. S. Blinder (Ed.), Paying for productivity: a look at the evidence (pp. 183-236). Washington: The Brookings Institution.

Liberty, B., \& Spector, J. (2009). We are smarter than me: how to unleash the power of crowds in your business. New Jersey: Wharton School Press/Pearson Education.

Likert, R. (1961). New patterns of management. New York: McGraw-Hill.

Locke, E. A. (2006). Business ethics: a way out of the morass. Academy of Management Learning \& Education, 5(3), 324-332.

Locke, E. A., \& Schweiger, D. M. (1990). Participation in decision-making: one more look. In L. L. Cummings \& B. M. Staw (Ed.), Leadership, participation and group behavior (pp. 137-212). Greenwich: Jai Press.

Malone, T. W. (2004). The future of work: how the new order of business will shape your organization, your management style, and your life. Boston: Harvard Business School Press.

Malone, T. W., Laubacher, R., \& Dellarocas, C. (2010). The collective intelligence genome. MIT Sloan Management Review, 51(3), 21-31.

O'Reilly, C. A., Caldwell, D. F., Chatman, J. A., Lapiz, M., \& Self, W. (2010). How leadership matters: the effects of leaders' alignment on strategy implementation. Leadership Quarterly, 21(1), 104-113. doi: 10.1016/j.leaqua.2009.10.008

O'Reilly, C. A., Harreld, J. B., \& Tushman M. L. (2009). Organizational ambidexterity: IBM and emerging business opportunities. California Management Review, 51(4), 75-99. doi: $10.1287 /$ orsc. 1090.0428

O'Reilly, C. A., \& Tushman M. L. (2011). Organizational ambidexterity in action: how managers explore and exploit. California Management Review, 53(4), 5-27.

O’Toole, J., \& Bennis, W. (2009). What's needed next: a culture of candor. Harvard Business Review, 87(6), 54-61.

Parker, S. K., Wall, T. D., \& Cordery, J. L. (2001). Future work design research and practice: towards an elaborated model of work design. Journal of Occupational and Organizational Psychology, 74(4), 413-440. doi: 10.1348/096317901167460

Pearce, J. A., \& Ravlin, E. C. (1987). The design and activation of self-regulating work groups. Human Relations, 40(11), 751-782. doi: 10.1177/001872678704001104

Pfeffer, J. (1998). The human equation: building profits by putting people first. Boston: Harvard Business School Press. 
Pfeffer, J. (2010). Building sustainable organizations: the human factor. Academy of Management Perspectives, 24(1), 34-45. doi: 10.5465/AMP.2010.50304415

Pfeffer, J., \& Sutton, R. (2006). Management half-truths and nonsense: how to practice evidencebased management. California Management Review, 48(3), 77-100.

Purser, R. E., \& Cabana, S. (1998). The self-managing organization: how leading companies are transforming the work of teams for real impact. New York: Free Press.

Schein, E. H. (1996). Three cultures of management: the key to organizational learning. MIT Sloan Management Review, 38(1), 9-20.

Shani, A. B., Grant, R. M., Krishnan, R., \& Thompson, E. (1992). Advanced manufacturing systems and organizational choice: sociotechnical system approach. California Management Review, 34(4), 91-111.

Sisson, K., \& Storey, J. (2000). The realities of human resource management: managing the employment relationship. Buckingham: Open University Press.

Slater, P., \& Bennis, W. G. (1964). Democracy is inevitable. Harvard Business Review, 68(5), 167176.

Srivastava, A., Bartol, K. M., \& Locke, E. A. (2006). Empowering leadership in management teams: effects on knowledge sharing, efficacy and performance. Academy of Management Journal, 49(6), 1239-1251. doi: 10.5465/AMJ.2006.23478718

Strauss, G. (1998). Participation works - if conditions are appropriate. In F. Heller, E. Pusic, G. Strauss, \& B. Wilpert, Organizational participation: myth and reality (pp. 190-219). Oxford: Oxford University Press.

Strauss, G. (2006). Worker participation - some under-considered issues. Industrial Relations, 45(4), 778-803. doi: 10.1111/j.1468-232X.2006.00451.x

Sutton, R. (2007). Building the civilized workplace. McKinsey Quarterly, (2), 30-39.

Sutton, R. (2009). How to be a good boss in a bad economy. Harvard Business Review, 87(6), 42-50.

Sutton, R. (2010). Why good bosses tune in to their people. McKinsey Quarterly, (3), 86-95.

Sydänmaanlakka, P. (2002). An intelligent organization. Oxford: Capstone.

Takeuchi, H., \& Nonaka, I. (1986). The new new product development game. Harvard Business Review, 64(1), 137-146. doi: 10.1016/0737-6782(86)90053-6

Tannenbaum, R., \& Schmidt, W. H. (1958). How to choose a leadership pattern. Harvard Business Review, 51(3), 162-180.

Trist, E. L. (1981). The evolution of socio-technical systems: a conceptual framework and an action research program. Toronto: Ontario Quality of Working Life Centre.

Ulrich, D. (1997). Human resource champions: the next agenda for adding value and delivering results. Boston: Harvard Business School Press.

Ulrich, D., Kerr, S., \& Ashkenas, R. (2002). The GE work-out. New York: McGraw-Hill.

Wall, T. D., Cordery, J. L., \& Clegg, C. W. (2002). Empowerment, performance, and operational uncertainty: a theoretical integration. Applied Psychology, 51(1), 146-169. doi: 10.1111/14640597.00083 
Welch, J. (2005). Winning. New York: Harper Collins Publishers.

Wickens, P. D. (1995). The ascendant organization. London: Macmillan Business.

Wilpert, B. (1998). A view from psychology. In F. Heller, E. Pusic, G. Strauss, \& B. Wilpert, Organizational participation: myth and reality (pp. 65-96). Oxford: Oxford University Press.

Wilpert, B. (2008a). Psychology and human factors engineering. Technology \& Work, 10(1), 15-21. doi: 10.1007/s10111-007-0073-0

Wilpert, B. (2008b). Regulatory styles and their consequences for safety. Safety Science, 46(3), 371375. doi: 10.1016/j.ssci.2007.05.010 